\title{
Farming in a challenging physical and social environment
}

\author{
R.J. ASPINALL \\ Box 94, Wanaka 9343, New Zealand \\ aspiringstation@gmail.com
}

My wife Allison and I farm Mt Aspiring Station located in high-country, $40 \mathrm{~km}$ northwest of Wanaka. We are the fourth generation of Aspinalls to farm the property since 1920. In that time our family has voluntarily surrendered 50000 ha to aid in creating Mt Aspiring National Park, traded another 7700 ha through the tenure review process and ended up with 2309 ha of freehold land. Currently, we winter 800 beef cattle, 5000 Romdale sheep, host two school lodges and have in excess of 100000 visitors across our land annually.

The property runs up the Matukituki Valley which is a glacial formed U-shaped valley. Farmland consists of cultivated river flats, broken terraces and steep, unstable hill slopes where vegetation has been burnt before oversowing, and where fertiliser is applied biennially. The property is $18 \mathrm{~km}$ long with the grazed area split by the Matukituki River and more than twenty creeks providing over $35 \mathrm{~km}$ of natural waterways accessible to stock. Combined with an annual rainfall of 2000 $3500 \mathrm{~mm}$ (from the homestead to the top boundary, respectively) this provides a challenge in terms of maintenance, stock movement and water quality.

With an altitude of 320 -1100 m a.s.l. and conditions mediated by a West Coast weather pattern, the winters are not as harsh as many other high-country areas. However, due to shading by the mountains, soil temperatures are slow to warm up in spring and lambing does not start until mid-October. With the large amount of annual rainfall the farm historically was regarded as summer safe. Nevertheless, the free-draining soils can go from saturated to serious moisture stress within a month. These free-draining soils (especially the river flats) have low natural fertility and nutrient holding capabilities, requiring tri-annual applications of fertiliser on crops and younger pastures.

To summarise, our physical challenges do not come from the average but arise from the variation or extremes climatically and topographically. For example, the Station received $13 \mathrm{~mm}$ of rain with northwest winds and $30^{\circ} \mathrm{C}$ days in November 2010 followed by $352 \mathrm{~mm}$ of rain in December, and did not see this as an overly abnormal occurrence.

Feed budgeting and pasture management is a difficult job in the best of conditions and when dealing with climatic extremes and land that cannot physically be subdivided, it can be nigh on impossible. In this problem lies the answer and while sometimes I feel we are making easy excuses, our system is designed around resilience and keeping expectations moderated. Stock policies include a medium stocking rate, high cattle ratio $(45 \%+)$ and adult stock, selling store lambs/ calves. This means a more resilient system capable of handling fluctuations in pasture growth and a wintering system based around cleaning up surplus long grass and seedhead left over from the summer and autumn.

With extensive development comes increased expectations around stock performance and effectively "making the development pay". At Mt Aspiring there is considerable potential for further development, however, we have elected to take the middle road by leaving some of the potential untouched while concentrating on getting the best out of our most productive areas, and the system we are running. This takes some of the pressure off in terms of land use and environmental effects (water quality, native bush margins, visual effects etc.) while creating a more resilient system where as a workforce, we are attempting to work with nature rather than striving for top $10 \%$ performance and fighting against it.

With personal satisfaction and family succession on the cards, business growth is still necessary and something we do not want to neglect. The farming operation on Mt Aspiring Station will always be the cornerstone of our business, however, we have elected for the majority of our growth to be off-farm through investment in separate farming operations, as well as commercial and residential property. The majority of on-farm growth is expected to come from the potential in tourism and related industries.

This potential for agri-tourism comes from the high number of domestic and international visitors that pass through the farm each year and lead us into social or human challenges. As mentioned earlier, it is estimated we have over 100000 visitors annually - either walking through to the National Park, taking part in a school visit or simply getting out of their car and strolling down to the river to throw rocks or have a picnic. We appreciate these visitors having the opportunity to visit our beautiful part of the world and do have many enjoyable interactions or receive positive feedback from many. However, such large numbers bring inevitable challenges.

Many of these challenges are simply related to the increase in numbers; such as the logistical issues of shifting stock and farm machinery when the farm lane is also the public road bisecting the property. Similarly, 
there are 10 different walkways through the farm that are used by recreational visitors and tourism operators. Many of these tracks run through the middle of the valley creating further issues and safety concerns while working with stock. Historically, visitors did not appear till mid-morning giving a window for farm work to occur, however, with increasing numbers and a rise in freedom camping, this window is steadily narrowing. I am lucky to have grown up with the increasing numbers, so I am fairly pragmatic about these delays and difficulties, although it is noticeable how frustrated friends or new staff can get with the tourist groups who insist on spreading out across the track so they can all get a photo of the lovely sheep.

In terms of managing this issue we have a strong relationship with the local Department of Conservation (DOC) office and our valley is a high priority for them. Following tenure review DOC was proactive in forming tracks, installing signage and erecting stiles next to gates. They continue to be proactive and most issues can be at least partially managed by sitting down and having a discussion with the local staff. We are also fortunate that a high proportion of our visitors are international tourists or recreational walkers with a specific walk in mind, as I believe these groups tend to stick to the tracks and obey signage.

One example of public ignorance is lambing closures. We have 3 week lambing closures on our tracks that pass through lambing blocks, but there are few practical ways to actually enforce them. The Roys Peak track through Alphaburn Station near Wanaka has a similar closure, however, despite a large sign sitting on the top step of the first stile and the carpark entrances being cordoned off with road cones, there are still people who ignore the message and walk the track.

These issues are symptomatic of the small proportion of people in any situation who behave badly. While it doesn't happen often we get gates left open (or unexpectedly shut), lambs turning up at home in cars because their "mum ran off", requests to help with vehicles stuck in fords, flat batteries or running out of petrol, people with sore ankles wanting a ride and others. These people are well meaning and I am usually happy to accommodate them, however, you also get more frustrating occurrences such as a group of young men chasing sheep in a paddock because "they just wanted to run with them", two men carrying a calf round to "stop it from jumping in the river" and two young ladies stuck in the river at $11 \mathrm{pm}$ because they had "hired a 4-wheel-drive vehicle and thought it would be fun to do some off-roading".

My growing concern is the interaction between environmental issues, public righteousness and social media. As mentioned, we have many cattle, a large distance of unfenced waterways, and at least $95 \%$ of our property can be seen fairly easily from public access ways. We are trying to be proactive environmentally by following our Level 3 Land Environment Plan, considering the environment within our management thinking and mitigating critical sources. We also test the river as it enters and leaves our property and are comfortable that our low density cattle access into a high flow, hard bottomed river is having minimal or no effect on the water quality.

Having said that, given general media coverage and Fonterra's claim that around $98 \%$ of their supplier's waterways have been fenced, I can understand why some people are confused or concerned when they see cattle with free access. What is frustrating, are people who do not try to understand the situation, but can garner immediate attention through social or mainstream media. I have never had a single stranger approach me on the farm and ask "I am concerned about those cattle in the river, why do you allow it?" yet I have had total strangers go straight to social media, National Radio, the front page of the Otago Daily Times and even the Prime Minister to demonstrate their outrage at this "terrible occurrence".

I believe this is a sad indication of the direction our society is heading and in my opinion, no better than schoolyard bullying (except that adults should know better). I can only speak positively about the support we have received from DOC and the Otago Regional Council (ORC) during these occurrences, however, there is still a significant mental toll incurred from dealing with these issues and worrying about when the next one will occur. Even with individuals who can better handle exposure such as this, it only leads to further polarisation rather than productive discussions about how we can all help improve water quality. A further negative is that in our case and in many others, we tend to focus on fixing the issues that can be easily seen by the public, rather than those that are hidden, but would provide the greatest environmental benefit.

As I previously discussed, we are fortunate that DOC is heavily involved with visitor management and a very low proportion of our visitors create intentional or unintentional issues. However, there is a storm looming related to the sheer number of visitors we now get and the growth that is forecast for the future. While only $0.1 \%$ of people may cause a problem $/ 10000$ visitors that is one issue a month; with a forecast 150000 visitors that translates to three issues a week. Even aiding well-meaning people who have made a genuine mistake becomes a serious drain on our time.

Numbers are also a major strain on infrastructure such as roading, rubbish bins, toilets, tracks and signage. We live and rely on $30 \mathrm{~km}$ of gravel road with a poor quality base, more than 10 fords and where rainfall events greater than $100 \mathrm{~mm} /$ day are not unusual. Over 


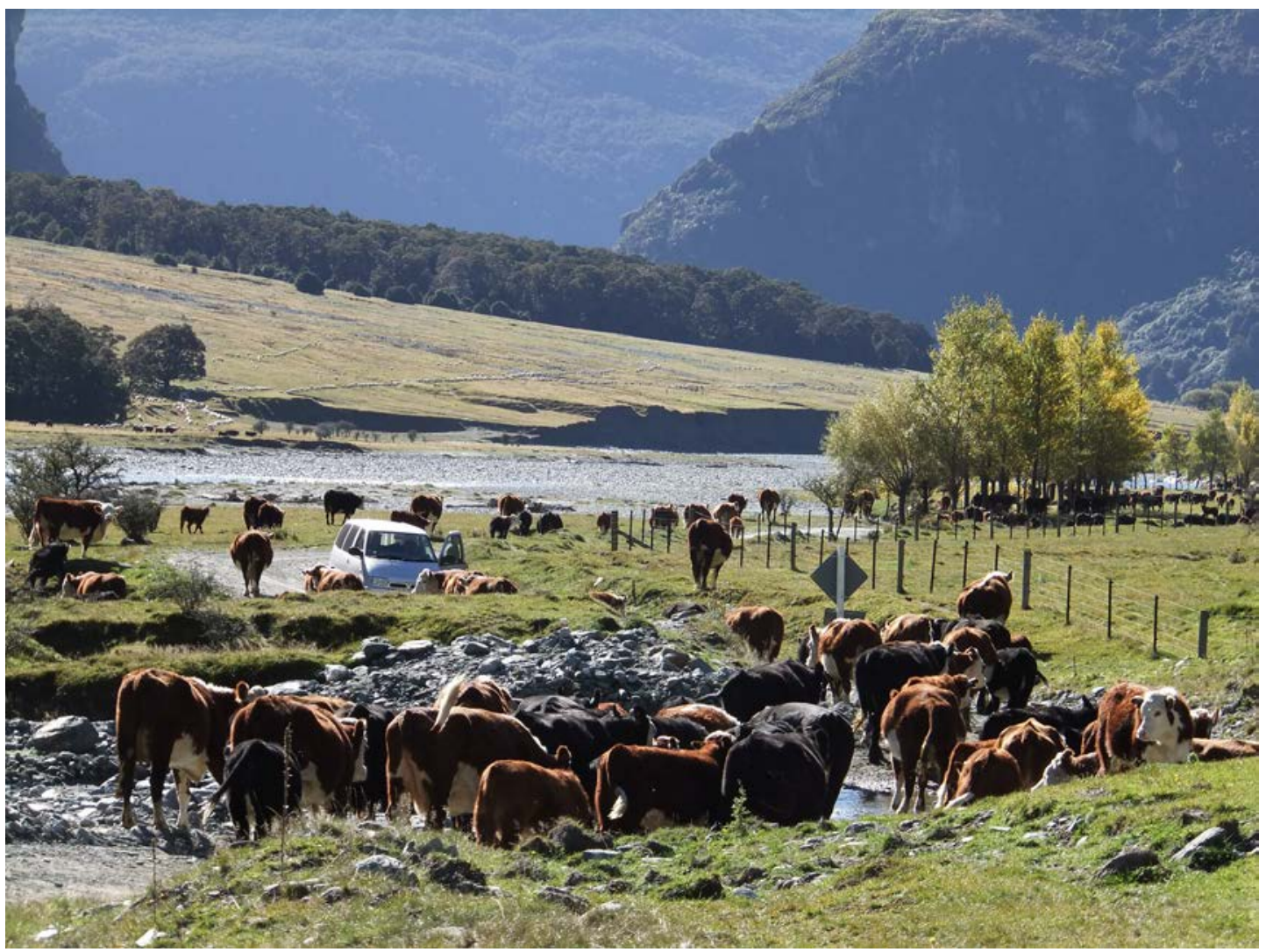

50000 vehicles use the road each year and despite this, the District Council is expected to maintain it with around $\$ 15000$ of roading rates collected annually from three ratepayers. It is no wonder that the first thing most people say when they arrive at our home is "how bad the road is".

The lack of rubbish bins and toilets is another issue with the increasing number of freedom campers, picnickers and the like. Queenstown Lake District Council (QLDC) work on the areas within the Wanaka town boundaries and DOC do what they can at their trailheads, but there is $50 \mathrm{~km}$ in between. It is under QLDC jurisdiction, most of the visitors are heading to DOC managed attractions and yet neither party has sufficient resources to manage this grey area to the level they would like. These issues occur frequently across the Queenstown Lakes, Central Otago and Mackenzie Districts and a cynical view is that while tourism is a "national treasure" many of the associated issues are not seen as a "national problem".

As a country it is important we have a conversation about where we are heading with tourism. Is the endless chase of "more tourists" the best option or do we need to think about limiting numbers so each visitor spends more and gets a better experience? I am told that on
Roys Peak there are already times you have to queue for 40 minutes to get a photo of the view - is this what we want New Zealand to be known as? We also need to talk about how we can ensure that the required infrastructure and services are paid for by our visitors and not the general public. We are repeatedly told how good tourism is for the New Zealand economy, however, when you drive past three tourists playing cards in their Australian owned rental van, while they cook 'Budget' noodles or lentils for tea, it is hard to see how much they are contributing to under pressure organisations such as Search \& Rescue and the emergency services.

On a farm scale I think we have to accept that change is inevitable. Much like I said we want to work with nature, we also need to work with the irresistible force that is globalisation and tourism. Instead of fighting against it we need to transition our business to take advantage of the opportunities that these visitors bring. This is not something that comes naturally to Allison and myself but there are many great examples throughout New Zealand of farming families that deliver innovative and enjoyable experiences to their visitors. There are also many successful businesses such as Wildwire Wanaka, Deep Canyon Adventures, Ridgeline Adventures and Minaret Lodge, that run high 
value tourist experiences through farmland in a way that minimises the impact on the farming operations.

We currently dabble in tourism, with the occasional film crew, access for tourism operators and a small ice cream caravan selling to the steady flow of traffic on the road. It is an area we need to expand. However, we are mindful that while it is easy to talk the talk it is much harder when actually faced with the challenges of staffing, customer service, marketing, health and safety, concessions, food safety regulations etc. We would prefer to embark on joint venture type enterprises with committed people who can deliver on these requirements, although we also recognise that the best returns are often made from taking control of your own business.

In summary, I love farming and we are extremely lucky to live in one of the most beautiful places in the world. Understandably, an increasing number of people also want to share this experience and while it creates challenges for us we must learn to live with and prosper from these changes, much as we have learned to work with the natural challenges we face. 